\title{
Overview of Concentrated Photovoltaic (CPV) Cells
}

\author{
Chukwubuikem Chukwuka, Komla Agbenyo Folly \\ Electrical Engineering, University of Cape Town, Cape Town, South Africa \\ Email: oluchux@yahoo.com
}

Received 30 August 2014; revised 20 October 2014; accepted 31 October 2014

Copyright (C) 2014 by authors and Scientific Research Publishing Inc.

This work is licensed under the Creative Commons Attribution International License (CC BY).

http://creativecommons.org/licenses/by/4.0/

(c) (i) Open Access

\begin{abstract}
Previous studies have shown that renewable energy is one of the effective ways to fight global climate change and emissions not to mention the increasing price of fossil fuels. Among the various renewable energy sources which include wind, solar, biofuel, geothermal and tidal waves, solar power has attracted much attention especially here in Africa because of the abundance of solar radiation. A lot of studies have been done on various photovoltaic (PV) cells ranging from silicon to thin film and most recently multi-junction solar cells. In this paper, we focused on concentrated photovoltaic cells (CPV) which are promising ways of converting solar energy to electricity. It is expected that if the most cost effective ways of converting solar energy to electricity is used, both the cost of installation and the running cost of concentrated photovoltaic cells will equate the utility grid electricity cost in a few years to come.
\end{abstract}

\section{Keywords}

Inverted Metamorphic Multi-Junction, Non-Imaging Optical Concentrator, Concentrated Photovoltaic Cells

\section{Introduction}

Most of the solar power systems in the market today can be divided into two major classes: the direct and the indirect solar power. The direct solar power refers to a system that converts solar radiation directly to electricity using a photovoltaic (PV) cell. The indirect solar power refers to a system that converts the solar energy first to heat and thereafter to electrical energy, as in the case of concentrated solar power (CSP). In a CSP plant, sunlight is focused on a heat exchanger; this heat is used to drive the turbine. The problems with these technologies are inefficiency and a very high capital cost. The typical efficiency of a CSP is about 15\% [1]. The highest efficiency of a silicon cell for example is $20 \%$. 
Concentrated photovoltaic (CPV) cell is the hybridization of the direct and the indirect solar power systems. In CPV, concentrated solar flux (about 300 suns) is focused on highly efficient solar cells such as the multijunction solar cell (about 40\% efficient). This results in a superior output many times that of the ordinary photovoltaics. The expensive solar materials in solar PV are replaced with mirrors and lenses made of cheap glass in CPV. The total efficiency of the entire system is about $35 \%$.

In this paper, we review different types of multi-junction solar cells, methods of concentrating light and the economy of scale that is capable of reducing the price of electricity produced from CPV within 5 years. It is expected that during this time frame, the costs of installation and running of the CPV will equate that of the grid electricity.

\section{Multi-Junction (MJ) Solar Cell}

Single junction solar cells are typically made of silicon semiconductor and are limited to $30 \%$ maximum efficiency because they have only one junction and one energy band. The first multi-junction was developed in 1990 by Boeing' Spectrolab [2] and it was made of GaInP/GaInAs/Ge on Germanium substrate with a record efficiency of $40.6 \%$ under 325 suns concentration. Consequently, other kinds of multi-junction solar cells have been built in a more cost efficient manner [3].

The multi-junction solar cells are designed to split the solar spectrum with many junctions. Here, thermalization losses are minimized. Two junctions have two energy layers typically, 1.6 and $0.9 \mathrm{eV}$. The materials used here could range from amorphous silicon, micro crystalline silicon, dye-sensitized, copper indium gallium selenide (CIGS) or organic semiconductors [4]. Triple junction splits the solar spectrum to three energy bands (1.8, $1.2,0.7 \mathrm{eV}$ ) with a maximum efficiency of $42 \%$ [4]. Four to six junctions have already been practically achieved [4]. Infinite junctions have theoretical efficiencies tending to $85 \%$, the thermodynamic limit. General limitations of solar cells include surface reflection, series resistance at contacts and recombination losses. Limitations specific to tandem solar cells are series-connection hence the need for current matching, variation of solar spectrum throughout the day, resistance in intermediate recombination layer, transmittance of top cells and light management with textured substrates [5].

\subsection{Metamorphic Multi-Junction Solar Cell}

In 1999, Fraunhofer ISE developed an MJ using groups III-V semiconductor compounds [6]. These cells are made out of thin Ga0.35In0.65P and Ga0.83In0.17 (band gaps $1.92 \mathrm{eV}$ and $1.87 \mathrm{eV}$ respectively) as layers on GaAs $(1.42 \mathrm{eV})$ or $\mathrm{Ge}(0.67 \mathrm{eV})$ substrates. These are grown by a method known as metamorphic growth on either Germanium or Gallium/arsenide substrate. In contrast to the conventional cells, these cells do not have the same lattice constant (i.e. the distance between the atoms in a crystalline structure are not the same). This makes it difficult to grow the III-V semiconductor layers with high crystal quality since at the interface of materials with different lattice constants, strain is present. This strain causes dislocation and other crystal defects. The researchers at Fraunhofer then localized the defects in a region not electrically active and the active region remains relatively free of defects [6].

Metamorphic Crystal Growth enables the use of a much larger range of III-V semiconductors. Different layers of the cell generate the same amount of current resulting in an efficient cell of about $41.1 \%$ efficiency at 454 suns

\subsection{Inverted Metamorphic Multi-Junction}

This is an improvement on the metamorphic cells which tends to improve the efficiency of the cell by reducing the band gaps of the GaInP and GaInAs. However, this causes a mismatch between the alloys and the Ge substrate thereby reducing the efficiency. Growth is inverted with the inverted metamorphic multi-junction solar cells relative to the conventional metamorphic multi-junction solar cells. The process used here is organometallic chemical vapour phase deposition. The top two layers are lattice matched. Attempt to grow the third metamorphic layer which is a mismatch to the first two layers leads to cell misfit and dislocation on the first two layers. This reduces performance of the entire system. This problem is solved by disposing a transparent step graded composition (AlGaInP) buffer in between the second layer and the metamorphic third layer and the grade is engineered to achieve a nearly strain-free metamorphic junction. Afterward the GaAs substrate is then re- 
moved and then reused as a template to grow another cell. Finally, MgF2/ZnS antireflective coating (ARC) is deposited by thermal evaporation and mounted on a handle.

This method of growing an inverted solar cell creates room for adding more junctions using the same template. The following are the advantages of the inverted multi-junction solar cells:

- Strain free metamorphic bottom layer without damaging the top lattice-combination.

- Possibility of lower cost by the reuse of the removed substrate, flexible and light weight.

- Rejection of unused infrared light for reduced heating [7].

The basic architecture of an inverted metamorphic multi-junction solar cell is shown in Figure 1.

\subsection{Quantum Well Aka Multiple Quantum Well (MQW) Structure}

A "quantum well" is a potential well that confines particles to two dimensions that are otherwise free to move in three dimensions. Both electrons and holes can be confined in semiconductor quantum wells. The effect is to increase the gain and efficiency of the solid state device such as lasers in CD or DVD players, infrared imaging, and more recently, solar cells. A quantum well is basically a semiconductor with a small energy gap (or band gap) sandwiched between two thicker layers of semiconductor(s) with a large energy gap, such as gallium arsenide (GaAs).

Quantum well solar cells are built with multiple nanoscale semiconductors layered on top of one another with a lateral conduction layer between the substrate and $\mathrm{n}$ region to allow contact between each device as shown in Figure 2. They are special multiband gap devices with intermediate properties between the hetero-junctions (the sum of the currents generated in different materials is the lower of the two) and tandem cells (sum of the voltages is determined by the worst of the two cells). It is known that quantum well solar cells (QWSCs) can enhance short circuit current and power conversion efficiency in comparison with similar, conventional solar cells made from the quantum well (QW) barrier material alone. Some designs have multiple quantum wells in the I-region of the p-i-n cells hence they are referred to as the multiple quantum well solar cells (MQWSC).

\begin{tabular}{|c|}
\hline Metamorphic 1.0eV IngaAs \\
\hline Transparent GalnP grade \\
\hline $1.4 \mathrm{eV} \mathrm{GaAs}$ \\
\hline $1.8 \mathrm{eV}$ GalnP \\
\hline GaAs Substrate \\
\hline
\end{tabular}

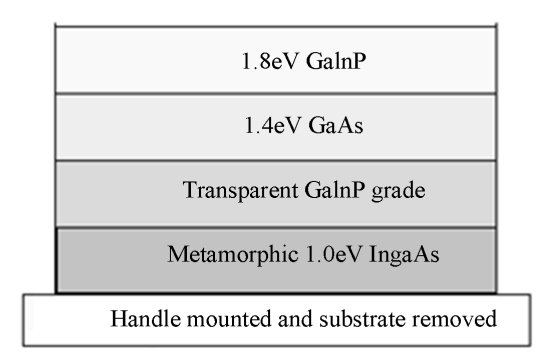

Inverted Growth

Figure 1. Inverted multi-junction solar cell [7].

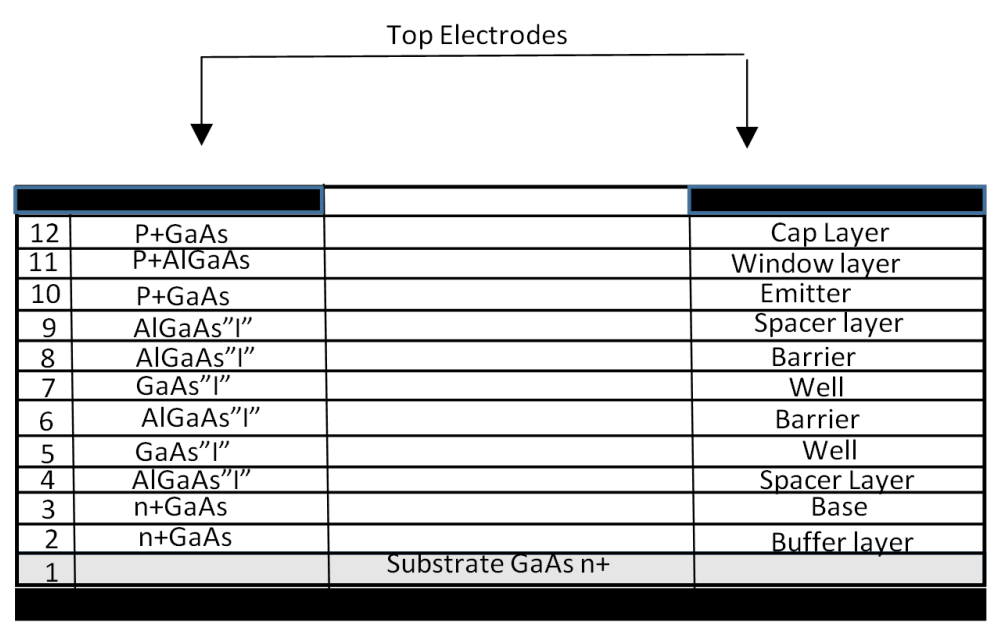

Figure 2. Multiple quantum well solar cells [8]. 
Keith Barnham [8] invented the quantum well solar cell in 1989. The solar cells developed by Barnham operate at high current [8]. The i region consists of alternating layers of Indium Gallium Arsenide (InGaAs) and Gallium Arsenide Phosphide (GaAsP), while the $\mathrm{p}$ and $\mathrm{n}$ layers of the solar cell are made from Gallium Arsenide(GaAs). A "strain balance" technique is used to grow the different layers, which matches the lattice structures of the different semiconductor materials, preventing defects. This method allows more than 65 wells to be grown on top of one another without dislocation [8]. MQW has a theoretical efficiency of over $50 \%$ but in practice only an efficiency of $29 \%$ has been realized.

\subsection{III-V/Silicon Lattice-Matched Tanem Solar Cell}

The newly discovered GaNPAs can be grown lattice matched to silicon substrate with very low structural defect densities and a band gap ideally suited for a high-efficiency multi-junction solar cell [9]. A two-junction device consisting of a $1.7-\mathrm{eV}$ GaNPAs junction on a $1.1 \mathrm{eV}$ silicon junction has the theoretical potential to achieve nearly optimal efficiency for a two-junction tandem cell. It has been demonstrated that a monolithic III-Von-silicon tandem solar cell in which most of the III-V layers are nearly lattice-matched to the silicon substrate. The cell includes a $1.8 \mathrm{eV}$ GaNPAs top cell, a GaP-based tunnel junction (TJ), and a diffused silicon junction formed during the epitaxial growth of GaNP on the silicon substrate. This tandem on silicon has a V/sub OC/of $1.53 \mathrm{~V}$ and an AM1.5G efficiency of 5.2\% without any antireflection coating. Low currents in the top cell are the primary limitation to higher efficiency at this point.

Silicon junction is formed during epitaxial growth of high crystalline quality lattice-matched GaNPAs on silicon by metal-organic vapour phase epitaxy (MOVPE). Two junction solar cells devices using this approach have the potential to reach efficiencies of $35 \%$ under the direct spectrum or $37 \%$ under the global spectrum [9]. So far, efficiency of $7 \%$ has been realized [9]. The structural diagram of III-V on silicon is shown in Figure 3.

\subsection{Lateral Spectrum Splitting Concentrator Photovoltaic (LSSCPV)}

LSSCPV solar cell uses a novel lateral or static optical concentrating system that splits incoming light into three different "energy bins" of high, medium and low, and directs them onto cells of different light sensitive materials that together cover the solar spectrum. Importantly, the concentrator is stationary with a wide acceptance angle optical system that captures large amounts of light and eliminates the need for complicated tracking devices.

Previous high-efficiency cells used a concentration device that required sophisticated tracking optics, a con-

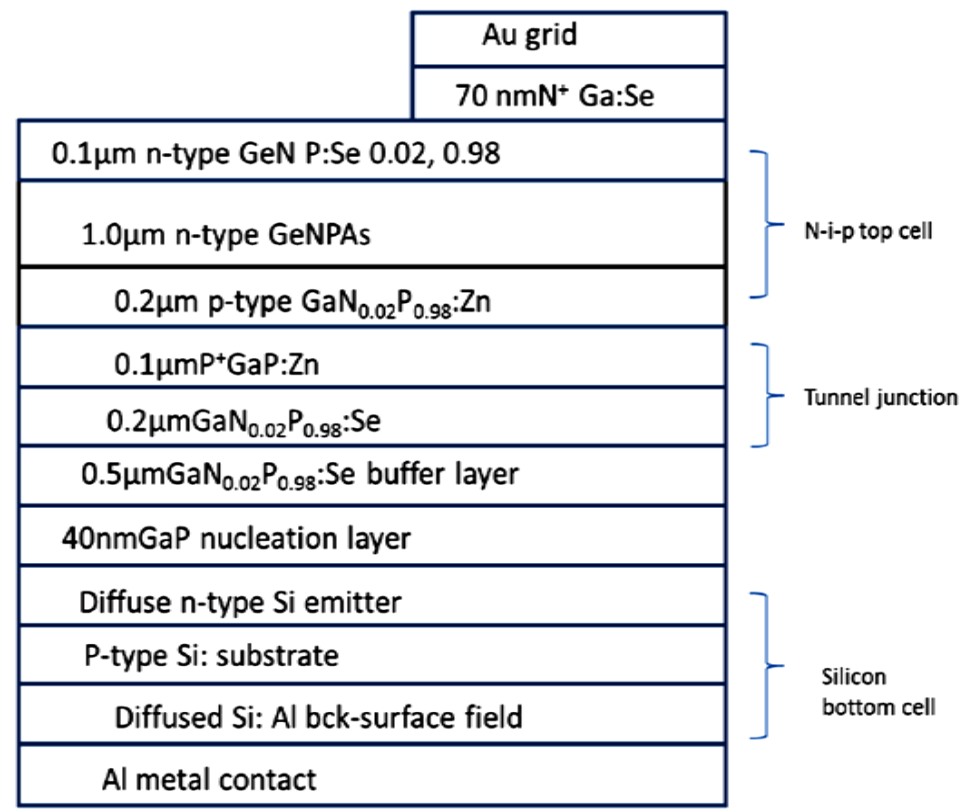

Figure 3. III-V-on-silicon tandem solar cell [9]. 
centrating lens the size of a table and were more than a foot thick. By contrast, the LSSCPVs are far thinner with less than 1 centimeter. The low profile and lack of moving parts translate into portability, which means these devices could easily be used with a laptop computer or a rooftop. A diagram of a LSSCPV is shown in Figure 4. These are:

- a front lens array using non-spherical lenses (toroids or crossed cylinders);

- a hollow pyramidal reflective concentrator array which increases the performance of the system for light which is not normal to the module;

- a non-imaging solid concentrator on the solar cell converting photon energies between $2.4 \mathrm{eV}$ and $1.4 \mathrm{eV}$ (called mid-energy solar cells); and

- Dichroic or trichroic prism which reflects the light above $1.4 \mathrm{eV}$ and passes light below this energy.

Further research suggests the use of InGaN for increased bandwidth (0.7 - $2.4 \mathrm{ev)} \mathrm{collection} \mathrm{and} \mathrm{improved} \mathrm{ef-}$ ficiency [10]. Because the cells are separate from each other the constraints of current and lattice matching do not apply. It allows the use of low cost materials such as silicon. LSSCPVs reduce the need for tunnel diodes and buffer layers. There is no need for tracking system when static concentrators are used. The system is portable and light therefore suitable for rooftop. The best efficiency achieved is $42.9 \%$ at 20 suns with $93 \%$ optical efficiency [10]. A typical cell composition for a three-cell system is GaInP (31.7\%), GaInAs/GaInAs (bottom filtered by $\mathrm{Si}$ ) (6.2\%), and silicon (filtered by GaAs) 5\%. The total efficiency is $42.9 \%$ [10].

\subsection{Dual Focus Cassegrainian Module (DFC)}

Dual Focus Cassegrainian module (DFC) is very similar to LSSCPV except that the dichroic mirror only isolates the low infra-red (IR) waves from the rest of the radiation. This low IR is captured with the Gallium Antimonide (GaSb) or InGaAs/InP otherwise known as the thermo photovoltaic (TPV) module is shown in Figure 5 and the spectral response is shown in Figure 6.

The thermophotovoltaic module has an added advantage of diverting the heat away from the IMM. The rest of the radiation is captured with the normal IMM cell. Here the expected efficiency is $46 \%$ [11].

\section{Concentrated Photovoltaic Cells (CPV)}

We discussed in the previous section various kinds of multi-junction solar cells which form an important component of a CPV. In this section, we will discuss various types of optical concentrators. These are passive, active and hybrid concentrators.

The non-imaging light concentrators are optical devices that have been optimized to transfer the maximum energy from the source to the target without attempting to form the image of the source on the target [12]. Con-

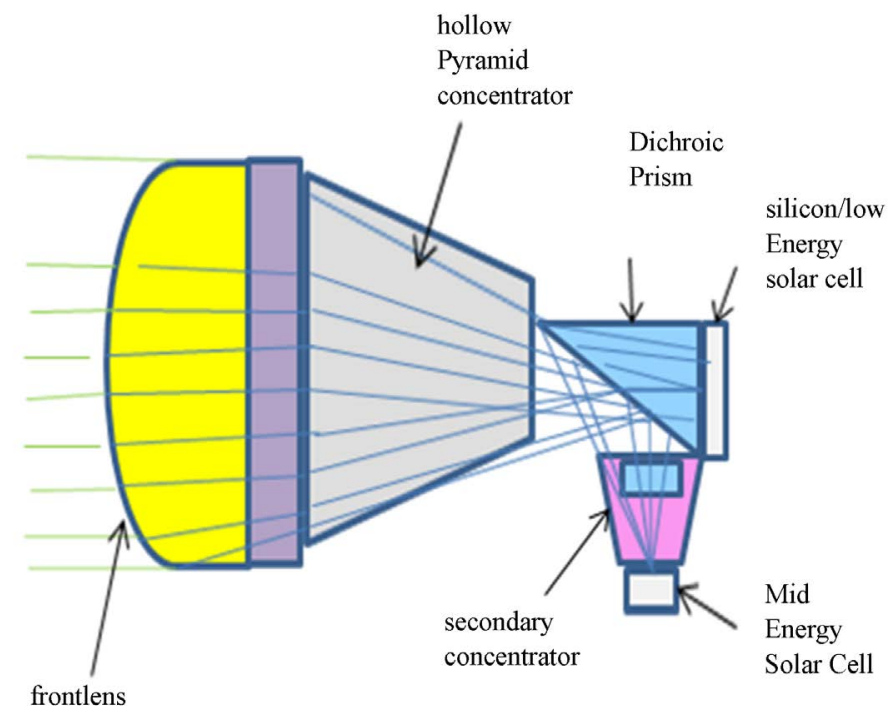

Figure 4. Lateral spectrum splitting concentrator photovoltaic cell [10]. 
centration in the excess of 1000 suns gives the highly concentrated photovoltaics (HCPV) [13]. Figure 7 illustrates that increased concentration of the sun on the solar cell enhances the performance leading to an increased the power output.

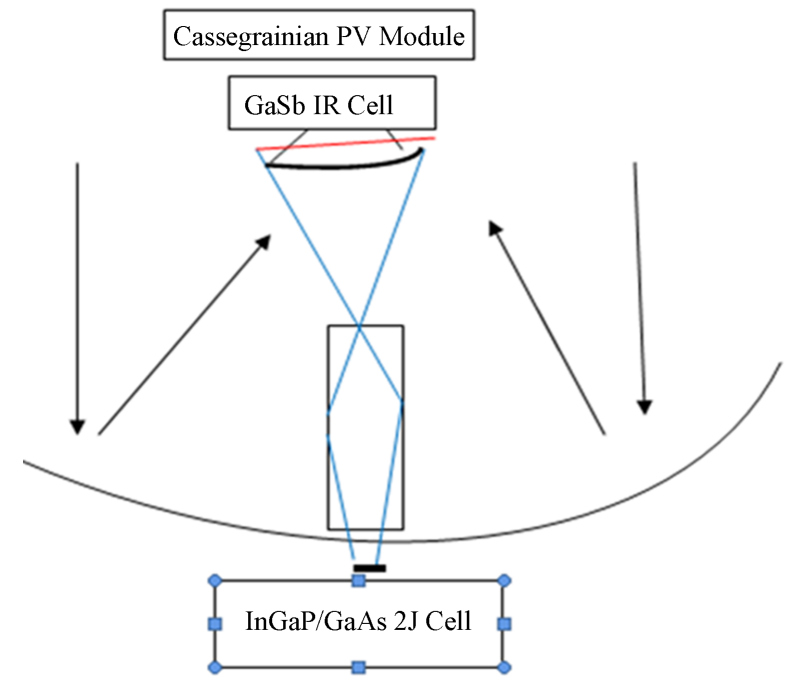

Figure 5. Dual-focus cassegrainian module concepts shown with first iteration InGaP/GaAs [11].

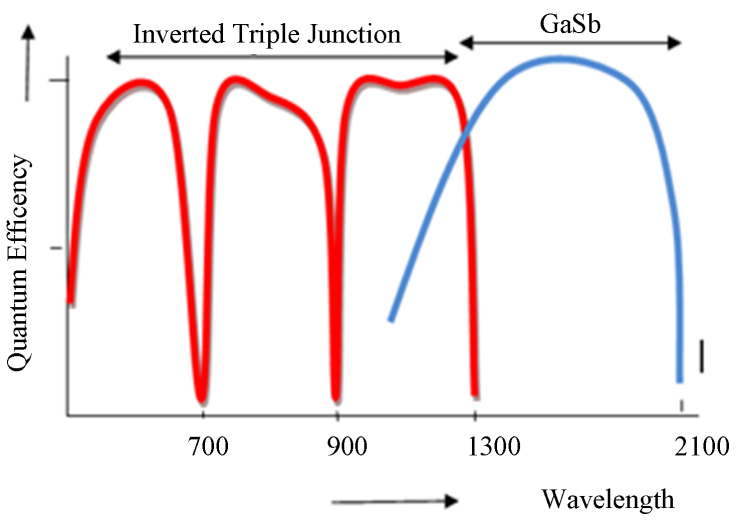

Figure 6. DFC Spectral responses [11].

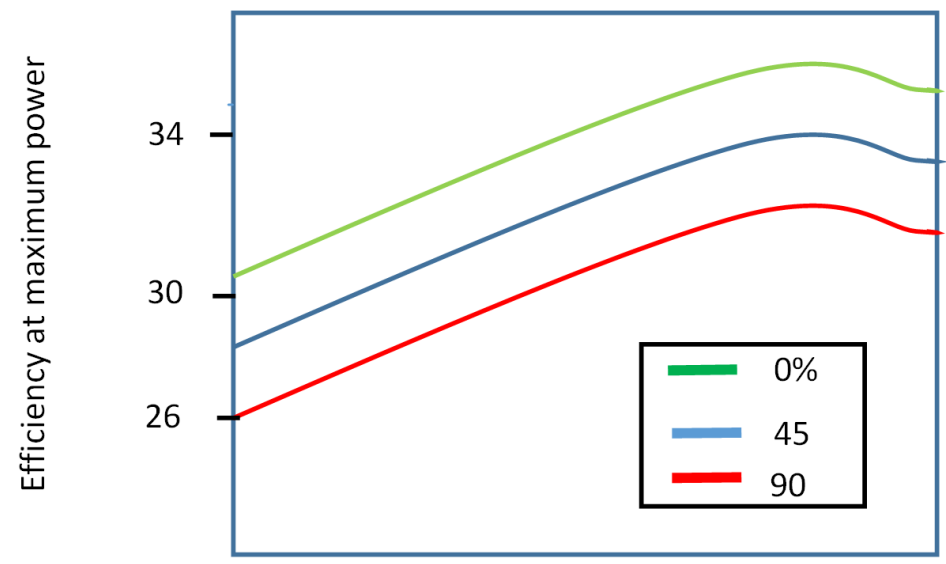

Figure 7. Efficiency/concentration charts [14]. 


\subsection{Geometric Concentrators}

These are non-imaging diffuse light concentrators that use geometry alone to reflect and refract light flux to achieve maximum transfer of flux at the expense of forming the image of the sun. They could be engineered to maximize the acceptance which eliminates the need for tracking while minimizing the area of the photovoltaic cell. A passive concentrator could focus light up to 1000 suns $\left(1 \mathrm{sun}=1 \mathrm{~mW} / \mathrm{m}^{2}\right)$ on to a cell of about $1 \mathrm{~mm}^{2}$. An example of a passive concentrator is compound parabolic concentrator (CPC). The concentrated light could be focused on the photovoltaic or on water to either produce steam or hydrogen [15].

\subsection{Active Concentrators}

These are fluorescent or luminescent concentrators that focus the sunlight by shifting the frequency from the high frequency to low frequency. They use special dye known as the lumagen dye or quantum dot to absorb the solar high velocity photons and emit them at a lower predetermined frequency which is then guided by total internal reflection to the solar cell [16].

\subsection{Hybrid Concentrators}

The hybrid concentrators combine the active and passive concentrators in cascade to produce ultrahigh flux regime for the production of the solar laser used for the production of hydrogen. Other designs of non-imaging optics include the simultaneous multiple surface method, three or two dimensional (SMS 3D or 2D). Each of these concentrators is capable of focusing the sun up to $\times 1000$ unto an efficient PV of area of between $1 \mathrm{~mm}^{2}$ to $1 \mathrm{~cm}^{2}$ can deliver up to $100 \mathrm{~W}$. The large acceptance angle eliminates the need of a tracking system. Solfocus is a pioneer producer of cheap concentrated photovoltaic solar cell [17].

\section{Key Features of CPV Geared towards Cost Reduction}

The CPV utilizes the most efficient solar cells such as multi-junction solar cells, inverted multi-junction solar cells, multiple quantum well, III-V on silicon, LSSCPV or Cassegrainian CPV. These cells guarantee superior outputs. Because the sun is concentrated this set up occupies less land space. Effective thermal management is applied to ensure uniform distribution of heat for absorption by the TPV. Hence the temperature of the system is always kept low (less than $400^{\circ} \mathrm{C}$ ). This eliminates the need of heat sink or an elaborate cooling system, all of which add to the cost of the installation. Some systems are designed with static concentrator with wide angle of acceptance in order to cut the cost of trackers.

Finally, to roll out the CPV in mass production, 6-axis robots and high speed material handling methods would be needed just like we have in high volume electronics industry today [18]. The CPV module costs at Solfocus over volumes are summarized Figure 8. These costs do not include the trackers or other balance of system items [18]. It is projected that within five years the cost of $1 \mathrm{GW} C P V$ farm would be less than $\$ 0.5 / \mathrm{W}$ from the current $\$ 1.5 / \mathrm{W}[18]$.

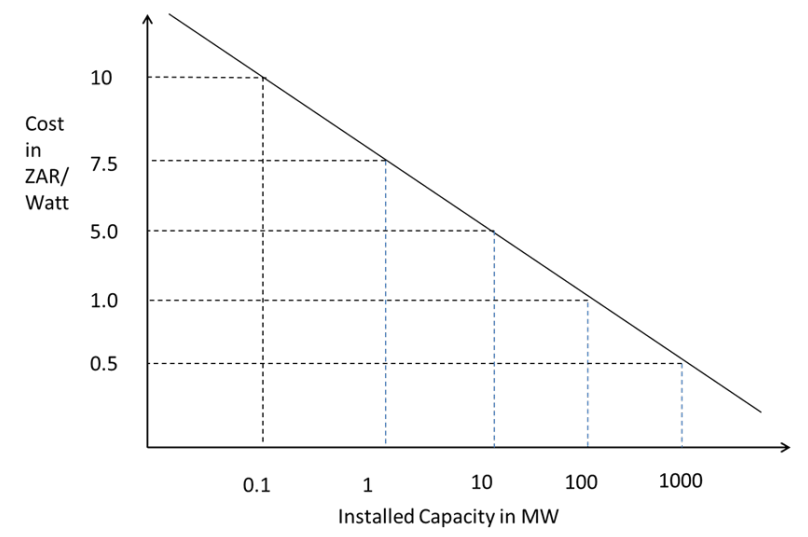

Figure 8. Solfocus second generation CPV cost/installed capacities [18]. 


\section{Acknowledgements}

This work is based on research supported in part by the National Research Foundation of South Africa UID 83977 and UID 85503.

The contributions of members of the Intelligent Power and Energy System (IPES) group are acknowledged.

\section{References}

[1] Newton, M. and Sen, P.K. (2010) Bulk Power Energy Storage and Concentrated Solar Power: Is There a Future in USA. Joint International Conference on Power Electronics, Drives and Energy Systems (PEDES) Power India, 1.

[2] Rittner, E.S. and Arndt, R.A. (2009) Comparison of Silicon Solar Cell Efficiency for Space and Terrestrial Use. Journal of Applied Physics, 47.

[3] Park, J. (2009) Nano-Solar Cells: Solar Cells of the Future with Nanotechnology. IEEE San Francisco Bay Area Nanotechnology Council.

[4] Wenger, S. (2009) Solar Photovoltaics and Energy Systems. Doctoral Course, E’colepolytechnique and Federale de Lausanne.

[5] Dimroth, F., Philipps, S.P., Peharz, G., Welser, E., Kellenbenz, R., Roesener, T., Klinger, V., Oliva, E., Steiner, M., Meusel, M., Guter, W. and Bett, A.W. (2010) Promises of Advanced Multi-Junction Solar Cells for the Use in CPV Systems. 35th IEEE Photovoltaic Specialists Conference (PVSC), Honolulu, 001231.

[6] King, R.R., Law, D.C., Edmondson, K.M., Fetzer, C.M., Kinsey, G.S., Yoon, H., Sherif, R.A. and Karam, N.H. (2007) 40\% Efficient Metamorphic GaInP/GaInAs/Ge Multijunction Solar Cells. Applied Physics Letters, 90, Article ID: 183516. http://dx.doi.org/10.1063/1.2734507

[7] Newman, F., Chumey, D., Pravin, P., Rick H., Tenorio, C., Aiken, D., Sharps, P. and Clevenger, B. (2009) Process in Adapting Inverted Metamorphic Solar Cell Technology for Terrestrial Concentration. 33rd IEEE PVSC, 1.

[8] Ekins-Daukes, N.J., Barnham, K.W.J., Connolly, J.P., Roberts, J.S., Clark, J.C., Hill, G. and Mazzer, M. (1999) Strain Balanced GaAsP/InGaAs Quantum Well-Solar Cells. Applied Physics Letters, 75, 4195-4197. http://dx.doi.org/10.1063/1.125580

[9] Geisz, J.F., Olson, J.M., Friedman, D.J., Jones, K.M., Reedy, R.C. and Romero, M.J. (2005) Lattice-Matched GaNPAs-on-Silicon Tandem Solar Cells. PVSC, 695-698.

[10] Wang, X. and Barnett, A. (2010) One Lateral Spectrum Splitting Concentrator Photovoltaic Architecture: Measurements of Current Assemblies and Analysis of Pathways to 40\% Efficient Modules. 35th IEEE PVSC, 002745-002750.

[11] Fraas, L.M., Avery, J.E., Strauch, J.E. and Girard, G. (2009) Dual Focus Cassegrainian Module Can Achieve $>>45 \%$ Efficiency. Photovoltaic Specialists Conference (PVSC), 2009 34th IEEE, 001169-001173. http://dx.doi.org/10.1109/PVSC.2009.5411226

[12] Pachon, D., Anton, I. and Sala, G. (2002) Rating and Modelling of Concentrator Systems. Conference Record of the Twenty-Ninth Photovoltaic Specialists Conference, 19-24 May 2002, 1600-1603.

[13] Yamaguchi, M. and Luque, A. (1999) High Efficiency and High Concentration in Photovoltaics. IEEE Transactions on Electron Devices, 46, 2139-2144. http://dx.doi.org/10.1109/16.792009

[14] Plesniak, A., Jones, R., Schwartz, J., Martins, G., Hall, J., Narayanan, A., Whelan, D., Benitez, P., Miano, J.C., Cvetkovic, A., Hernandez, M., Dross, O. and Alvarez, R. (2009) High Performance Concentrating Photovoltaic Module Designs for Utility Scale Power Generator. 34th Photovoltaic Specialists Conference (PVSC), 7-12 June 2009, 2231-2236.

[15] Horne, S., Couley, G., Gordon, J., Fork, D., Meada, P., Schrader, E. and Zimmerman, T. (2006) A Solid 500 Sun Compound Concentrator PV Design. IEEE 4th World Conference on Photovoltaic Energy Conversion, 1, 694-697.

[16] Minano, J.C., Gonzalez, J.C. and Zanesco, I. (1994) Flat High Concentrator Devices. Conference Record of the Twenty Fourth IEEE PVSC, Photovoltaic Energy Conversion, 1, 1123-1126.

[17] Scherbatyuk, G.V., Inman, R.H., Wang, C., Winston, R. and Ghosh, S. (2010) Viability of Using Near Infrared Lead Sulfide Quantum Dots as Active Material in Luminescent Solar Concentrators. Applied Physics Letters, 96, 191901. http://dx.doi.org/10.1063/1.3422485

[18] Sakuta, K., Sawata, S. and Tanimoto, M. (1994) Luminescent Concentrator Module of a Practical Size. Conference Record of the Twenty Fourth, IEEE PVSC, Photovoltaic Energy Conversion, 1, 1115-1118. 
Scientific Research Publishing (SCIRP) is one of the largest Open Access journal publishers. It is currently publishing more than 200 open access, online, peer-reviewed journals covering a wide range of academic disciplines. SCIRP serves the worldwide academic communities and contributes to the progress and application of science with its publication.

Other selected journals from SCIRP are listed as below. Submit your manuscript to us via either submit@scirp.org or Online Submission Portal.
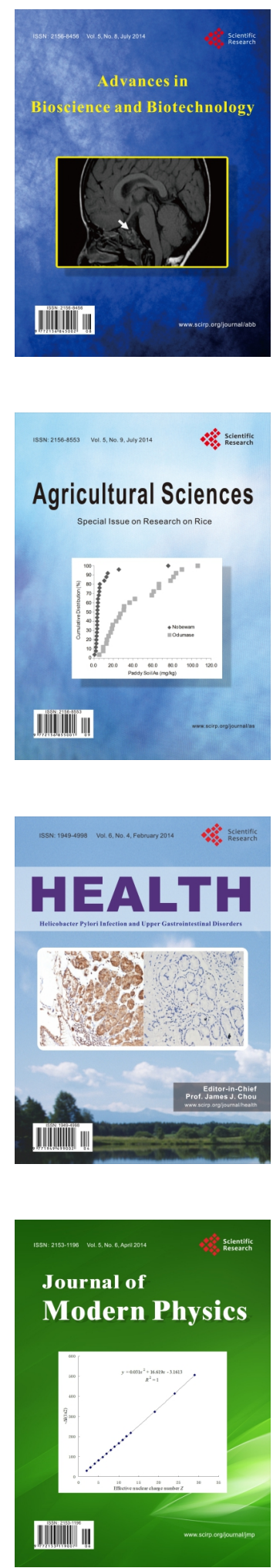
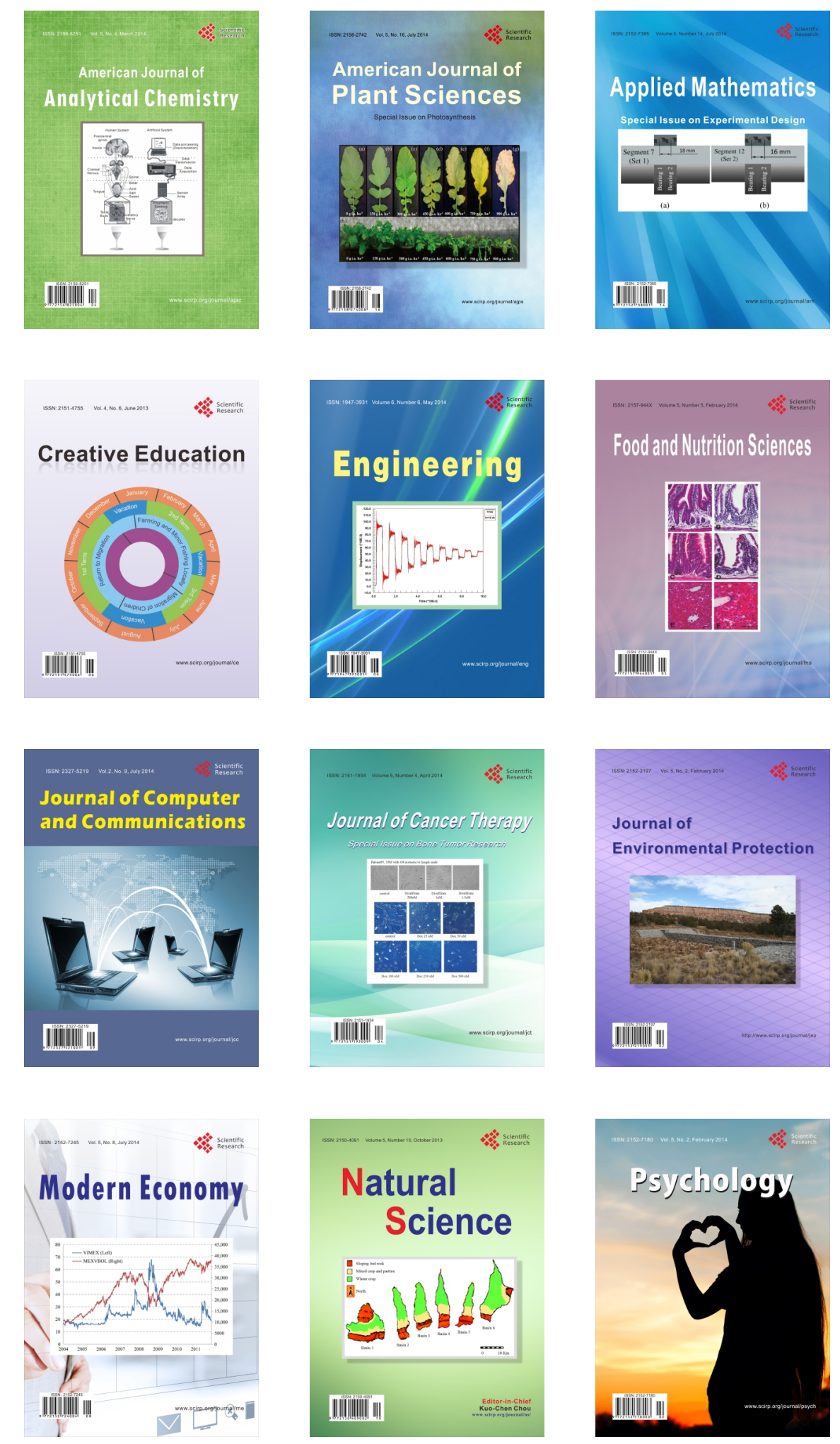